\title{
El refrán: un artefacto cultural
}

\section{EL ENFOQUE ETNOLINGÜISTIICO EN EL ESTUDIO DEL REFRÁN}

Muchos son los estudios que sobre el refranero se han publicado. Sin embargo, no son tantos los que profundizan en el aspecto etnolingǘstico del mismo, de innegable interés. Lo que con este trabajo se pretende es, pues, subsanar en alguna medida este hecho.

Realmente merece atención el hecho de que un pueblo refleje su conjunto de normas de convivencia, amén de otros tipos de reglas, a través de una manifestación lingüística de características tan explícitas y exclusivas como es el refranero. De ello se deduce que éste forma parte de una ideología, entendiendo este concepto como «el sistema de representaciones (ideas, conceptos, imágenes, mitos, etc.) que reflejan en el nivel de la conciencia subjetiva, la organización objetiva de la sociedad en un momento histórico» '.

Una de las definiciones de refrán que mejor reflejan su esencia es la que dio J. Casares en su Introducción a la lexicografía moderna:

Es una frase completa e independiente, que en sentido directo o alegórico, y por lo general de forma sentenciosa o elíptica, expresa un pensamiento - hecho de experiencia, enseñanza, admonición, etc.- a manera de juicio, en el que se relacionan por lo menos dos ideas ${ }^{2}$.

Se trata de una definición precisa que condensa varios aspectos, dado que atiende tanto al lingüístico - léxico y semántico- como al cultural. Y ello es interesante porque el refrán puede estudiarse, como más arriba se ha mencionado, desde diversos ángulos. Quizá el enfoque más habitual sea el puramente lingüístico, que, a la vez, resulta también el más aséptico -aunque importante y necesario-, por atender tan sólo al aspecto formal de la cuestión. Así tratan el tema los estructuralistas. Para Coseriu, por ejemplo, los refranes forman parte de lo que él llama «discurso repetido» ${ }^{3}$,

$1 \quad$ Nueva Enciclopedia Larousse (Barcelona, 1983), T. 10, p. 5068.

2 J. CASARES, Introducción a la lexicografía moderna. Cap.: «La frase proverbial y el refrán» (RFE. Anejo LII. Madrid, 1969), p. 194.

3 E. Coserru, Principios de Semántica Estructural. Cap.: «Introducción al estudio estructural del léxico» (Madrid, 1981), p. 113. 
cuyo estudio queda, a su entender, fuera de la gramática y la lexicología, dado que no son estructurables por su incapacidad para serles aplicado el principio de conmutabilidad. Así, los elementos de las expresiones fijas tan sólo significan «en bloque», no individualmente.

Los lingüistas estudian aquello que se refiere a la forma del refrán: su estructura, su sintaxis, su fonética. Esto les llevará también a una cuestión polémica que trasciende el terreno de la pura lingüística: ¿puede considerarse el refrán como literatura? A este respecto Coseriu afirma que «los refranes son una forma de la literatura popular española» ${ }^{4}$, principalmente debido a esa característica suya de interpretabilidad en bloque. También para Julio Cejador los refranes pertenecen a la literatura tanto como a la filosofía, «mezclando utile dolce»'. Para Lázaro Carreter, por el contrario, aquéllos tan sólo pertenecen al folklore de un pueblo y descarta por completo que ese «lenguaje literal», como él los llama, tenga algo que ver con la creación literaria, ni aun en los primeros eslabones de ésta ${ }^{6}$.

El enfoque etnolingüístico, por su parte, se basa en consideraciones que reflejan la relación entre el hombre y su cultura y el lenguaje, a una de cuyas parcelas pertenece el refranero. Para ver la forma en que esta relación se establece deberemos primeramente abordar cuestiones como qué es cultura popular o folklore y cómo se realiza el trasvase al terreno de la lengua, de este aspecto de la vida del hombre.

\section{Cultura Popular y lenguaje}

Es necesario delimitar, en primer lugar, los términos de «cultura» y «cultura popular». Naturalmente, la cultura popular forma parte de ese concepto tan amplio que es cultura. Pero hay que matizar.

En un tiempo hubo quien dio a este concepto un cariz evolucionista; así, el desarrollo humano en el tiempo y en el espacio se extendería desde las sociedades más primitivas, «aculturales», hasta las más avanzadas, las de mayor «evolución cultural». A diferentes etapas de la evolución corresponderían, pues, distintas sociedades '. Sin embargo, pronto se vio que no era éste el mejor método para abordar el estudio de la cultura humana

4 Ibidem, p. 115.

5 Citado por F. C. SÁINZ DE RoBles, en Refranero español (Madrid, 1944).

6 F. LAZARo CARreter, "Literatura y Folklore», en Estudios de Lingüística (Barcelona, 1980), pp. 207-217.

7 Ver W. Goodenough, «Cultura, lenguaje y sociedad» (1971), en J. S. KAHN, El concepto de cultura. Textos fundamentales (Barcelona, 1975), p. 190. 
desde una perspectiva antropológica. Fue Franz Boas quien se percató de ello y trató de demostrar que cada colectividad puede tener, y de hecho tiene, su propia cultura, independientemente de cualquier comparación con el eventual desarrollo de otras comunidades. Se definiría, pues, la cultura «como el conjunto diferenciado de costumbres, creencias e instituciones sociales que parecen caracterizar a cada sociedad aislada» ${ }^{8}$. Visto así, el adjetivo «popular» resulta redundante, sobre todo para los antropólogos quienes lo usan poco o nada. Sin embargo, entre los investigadores de otras disciplinas sí suele hacerse la distinción, ya que, dada la amplitud del término, el sustantivo a secas podría resultar poco preciso.

Otro término que debemos mencionar es «folklore», que consideraremos como sinónimo del anterior, ya que su etimología remite exactamente a «saber popular». Y de saber popular se ha calificado al refranero. En consecuencia, es acertado suponer que éste se inscribe en el marco del folklore español y no en el de la creación literaria. La literatura de un pueblo forma parte de su cultura, no teniendo por qué - aun cuando algunas de sus variantes tengan puntos de contacto con las tradiciones populares (literatura oral, por ejemplo) - haber transcurrido por la vía folklórica para manifestarse. Todo lo contrario le ocurre al refranero que constituye una de las más puras manifestaciones de la tendencia a reflejar en el lenguaje, determinadas creencias y tradiciones, por parte de los miembros de una sociedad.

Esto nos conduce a la cuestión de la influencia de la cultura sobre el lenguaje. Aunque fue Whorf quien llamó la atención sobre el hecho de que, de alguna manera, era la lengua la que configuraba la experiencia humana, no es menos cierto que, una vez determinadas las estructuras básicas de cada lengua y ya en un nivel superior de creación lingüística, es esa experiencia del mundo real, particular de cada zona, es decir, la cultura propia, la que influye y deja su huella en las manifestaciones lingüísticas de una comunidad.

Vemos, pues, la íntima interacción que se establece entre lenguaje y cultura popular, así como la gran importancia de aquél en la vida cotidiana del hombre. Tanto es así que, en algunos aspectos, determinadas construcciones lingüísticas pueden llegar a convertirse en fetiches, no materiales sino ideológicos. Del poder esotérico del lenguaje nos hablan las formas rituales, las hechicerías y las palabras tabús. Evidentemente, esos son los casos extremos de esta faceta de la lengua. No hace falta ir tan lejos para encontrar esta característica en una manifestación lingüística: los refranes la poseen. La prueba de ello está precisamente en el gran valor

\footnotetext{
$8 \quad$ Ibidem, p. 190.
} 
de verdad indiscutible que se les ha atribuido por parte de muchos de los que los han estudiado.

Los primeros que se ocuparon de ellos fueron el Marqués de Santillana, que tituló su recopilación Los refranes que dicen las viejas tras el fuego, esto es calentándose a la lumbre por el orden de a b c (1508), y Juan de Valdés, quien los propuso como modelo de la lengua de uso corriente en su obra Diálogo de la Lengua (1536). Otros eruditos se dedicaron también a la recopilación de refranes durante los siglos XVI y XVII. Así, Juan de Mal Lara publica en 1568 su Pbilosophia Vulgar, obra en la cual califica a los refranes de «piedras preciosas salteadas por ropas de gran precio que arrebatan los ojos con sus lumbres» ?. Hernán Núñez de Toledo, también llamado «el Pinciano», López de Velasco, Sebastián de Horozco, Lorenzo Palmireno y Pedro de Vallés son algunos de los estudiosos que se ocuparon del tema, en la misma tónica.

Ya en nuestro siglo, la línea ha sido similar: numerosas e importantes recopilaciones, algunas dedicadas a un solo tema ${ }^{10}$ y otras de carácter más general, así como estudios más o menos críticos acerca del tema. han sido publicados. Entre estos últimos hemos observado cómo la gran mayoría manifiesta esa actitud reverente y de total acatamiento para con las consignas del refranero. Frases como «El refranero español condensa el saber del Viejo Mundo» ${ }^{11}$, «... sus enseñanzas son admirables y sabias. Muchos refranes responden a un sentido humano y moral, como una religión» ${ }^{12}$, se prodigan en estos estudios. Los propios refranes dejan ver esa tendencia: «No hay refrán que no sea verdadero», «Voz del pueblo, voz del cielo» ${ }^{13}$.

Todo ello hace, como hemos dicho, que el refranero, dada la cultura en que se ha generado, haya adquirido matices fetichistas, llegando en ocasiones a la superstición. En cualquier caso, es innegable que el refrán es un artefacto cultural que en su vertiente ideológica es interesante estudiar.

9 Citado por Gómez Tabanera, El folklore español. Cap.: «El refranero español» (Madrid, 1968), p. 400.

10 Obras monográficas referidas al refranero son las compuestas por A. Castillo de Lucas, médico, sobre medicina popular y por J. Gella Iturriaga, marino, sobre la vida marinera, entre otras.

1 Ver Gomez TABANERA, op. cit. p. 389.

12 Ver T. Álvarez ANGulo, «El refranero español y su sabiduría». Conferencia pronunciada en La Sorbona. Abril de 1953 (Madrid: José Porter, editor, 1953).

13 Todos los refranes citados en este trabajo proceden de las siguientes recopilaciones: Nueva Enciclopedia Larousse (Barcelona, 1982), s.v. REFRÁN. Tomo 16, pp. 83648370; F. Maldonado, Refranero clásico español (1960) (Madrid, 1982), y J. M.2 SBARBI, El refranero general español (1874) (Madrid, 1980). 


\section{EL CARÁCTER INSTRUMENTAL DEL REFRÁN}

En primer lugar hay que diferenciar el concepto de cultura de sus productos. La cultura es lo que se aprende, es todo aquello que es preciso saber para observar las normas y actitudes mentales que una sociedad mantiene. Naturalmente, este conjunto de ideas interiorizado en cada uno de los individuos de esa sociedad, tiene su correspondiente salida al exterior, es decir, se manifiesta de alguna forma. Y lo hace en lo que Goodenough llama «artefactos culturales». Destaca este autor el hecho de que una máscara de África Occidental no se percibe de la misma forma en su propio contexto cultural que en un museo, por lo que añade:

Como entidad material, la máscara no ha cambiado, pero lo que es a ojos del espectador, depende de su experiencia: de las cosas que haya aprendido. Así vemos que las diferencias culturales entre los hombres no consisten simplemente en las cosas que observan, sino en las normas con arreglo a las cuales las observan ${ }^{14}$.

De esto se deduce que hay que distinguir entre aquello que vamos aprendiendo de la tradición y lo que luego somos capaces de hacer con ello.

Lo mismo puede aplicarse al lenguaje. La lengua es aquello que aprendemos, mientras que el habla, la actualización de la lengua realizada por el hombre, es un producto de ésta. En consecuencia puede decirse que los refranes participan tanto de las características de artefacto cultural is como de realización lingüística. Esto queda representado en el esquema siguiente:

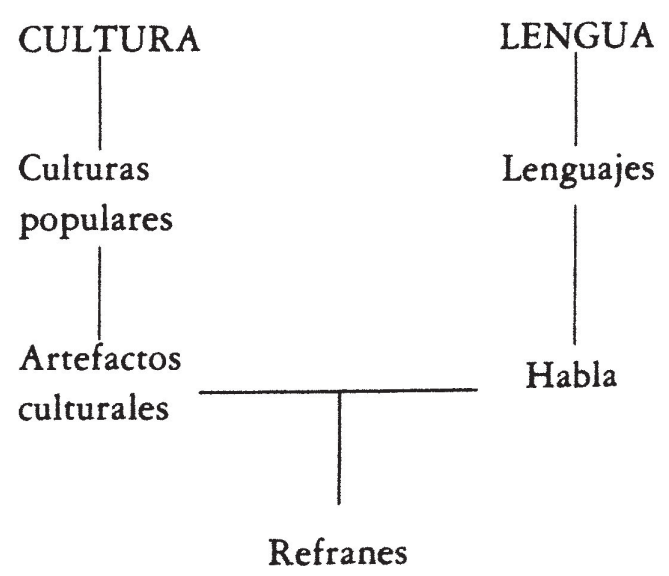

14 Ver W. GoOdenough, op. cit., p. 191.

15 El mismo Goodenough afirma que los productos culturales no sólo se limitan a los objetos materiales, sino que también puede tratarse de «objetos» sociales y/o ideológicos. 
Pero no debe considerarse este esquema como indiscutible e inalterable. El mismo Goodenough reconoce que, en ocasiones, la diferencia entre cultura y artefactos puede resultar de difícil delimitación:

Debemos reconocer que cualquier artefacto cultural, una vez creado, puede convertirse en modelo, para la creación de otros artefactos, sumándose su idea a la masa de normas de cultura ${ }^{16}$.

Esto parece también haber ocurrido con el refranero: su propio carácter instrumental le convierte en modelo mismo, todo ello dentro de una cultura dada, la española.

\section{CLASIFICACIÓN DEL REFRANERO SEGÚN LA INTENCIONALIDAD}

No todos los refranes persiguen un mismo fin. Así, de acuerdo con la intencionalidad, el refranero es susceptible de clasificación.

Hay refranes que tan sólo informan o pretenden informar de algo, sea cierto o no. Normalmente, los refranes de carácter agrícola pertenecen a este grupo. Podemos citar refranes tan conocidos como «Cuando marzo mayea, mayo marcea», muy interesante desde el punto de vista de la creación lingüística, o "Cielo borreguero, vendaval o agua del cielo», "Abril, aguas mil» y muchos más. Se integran también aquí los de carácter médico. Tenemos, por ejemplo: «Al catarro, con el jarro». En general, todos los que se refieren a una actividad determinada (agricultura, medicina, vida marinera, etc.) son refranes que tan sólo pretenden transmitir una información que se quiere provechosa para todos y que condensa un saber surgido, por lo general, de la observación. El carácter instrumental de este tipo de refranes es, en consecuencia, absolutamente patente. Podrían compararse con ciertas hierbas de carácter curativo empleadas por determinados grupos, en lo cual coexisten dosis de realidad con dosis de superstición.

Pero hay que destacar el hecho de que este tipo de instrumentos culturales sirve a unas determinadas parcelas, muy concretas, de la cultura popular; son refranes de cariz, llamémosle, tecnicista.

Es de señalar también la característica, referida al contenido simbólico, de que goza este tipo de refranes. Puede decirse que no presentan doblez alguna. Cuando se dice «Abril, aguas mil», significa que este mes suele ser muy lluvioso y nada más. Hay figura retórica, sí, pero sin doble sentido ni alusión a otras esferas por medio de la connotación.

$16 \quad$ Ibidem, p. 191. 
Existe otro gran grupo de refranes que lo que hace es transmitir una ideología. Y esos son los que nos interesan. Se trata de los que están relacionados con las normas de conducta y las costumbres, así como los que atañen a instituciones sociales, ámbitos de la organización objetiva de la sociedad que inciden de forma especial en la conciencia subjetiva de los miembros de aquélla.

Incluiremos también aquí aquellos refranes que, si bien no se refieren a normas de conducta ni a instituciones ni a parcelas determinadas de la actividad humana, suelen presentar una actitud irónica, incluso sarcástica, ante un suceso o situación determinada. $\mathrm{Y}$ lo hacemos porque son asimismo transmisores de un imaginario social y, en ocasiones, contrapunto de aquellos otros que marcan las pautas a seguir. Nos referimos a refranes del tipo: «Mala noche y parir hija» cuya glosa reza: «... expresa haber tenido mal éxito en un negocio o pretensión, después de haber aplicado el mayor trabajo y cuidado para conseguirlo» ${ }^{17}$. Vemos cómo este refrán sirve para exclamar ante una situación de fracaso; sin embargo, la connotación que encierra la frase "parir hija» es testimonio claro de una ideología muy concreta. El mismo refrán con «hijo» en lugar de «hija», cambiaría de tal forma su sentido que dejaría incluso de tenerlo.

En consecuencia, puede establecerse una clasificación del refranero según el esquema siguiente:

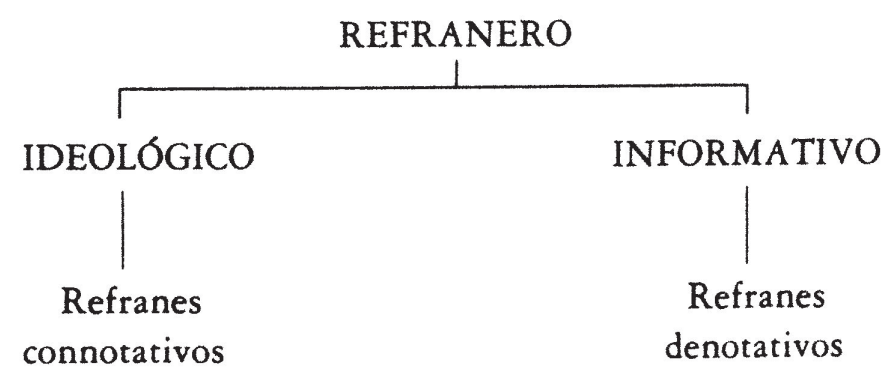

Si decíamos que los refranes de tipo informativo mostraban un patente carácter instrumental, lo mismo puede afirmarse de los de tipo ideológico, en los que se refleja una ideología que se revela conservadora y represora, como veremos más adelante. Precisamente, los detractores del refrán lo han sido por esta característica suya. El padre Feijóo, el «desengañador de las Españas» ${ }^{18}$, los combatió como una forma más de la ignorancia y la superstición del pueblo que debía erradicarse. Ya en nuestros días, Lázaro

17 Ver Nueva Enciclopedia Larousse. T. 16, p. 8367.

18 Ver J. Marichal, Teoría e bistoria del ensayismo bispánico (1957) (Madrid, 1984), pp. $90-101$. 
Carreter los cita como una «anomalía del lenguaje» ${ }^{19}$, congratulándose de su poca incidencia en el habla actual.

\section{EL REFRANERO: UNA ALEGORÍA}

Observaremos ahora cómo opera el refrán y para ello hay que detenerse en su contenido semántico, clave de su interpretación. Así, consideraremos el refrán como un mensaje, portador de una información, que deberá ser codificado por el receptor. Para ello una serie de mecanismos se ponen en juego.

El refrán, dentro de una teoría de la comunicación que contemple tanto la información verbal como la no verbal, debe ser tratado como un «indicador» equivalente a elementos, como, por ejemplo, el humo, en tanto que indicio de fuego. Así, tendremos:

$\frac{\text { HUMO }}{\text { FUEGO }}=\frac{\text { REFRÁN }}{\text { VALOR SIMBÓLICO }}$

Pero la diferencia entre ambos está en que el humo es un indicador natural en el que el hombre no ha influido para nada, mientras que las conexiones establecidas en la segunda relación pertenecen al campo de las asociaciones arbitrarias establecidas por el hombre. Naturalmente, en este caso, dicha asociación descansa sobre los principios lingüísticos que atañen no sólo a los refranes sino a toda la comunicación lingüística humana.

El refrán es, pues, un tipo de signo que podemos definir como simbólico. Pero ¿qué clase de símbolo? Es una característica básica del refrán el hecho de que se trata de una premisa aceptada por todos los miembros de una comunidad. En consecuencia, podemos hablar de él como de «símbolo estandarizado», en oposición a otros símbolos individualizados, como, por ejemplo, las metáforas, productos de un solo creador, el autor literario, y que, aunque tengan éxito y lleguen a difundirse entre la comunidad hablante, deben mantenerse en la misma forma en que fueron creadas puesto que sólo así tienen valor. Por otra parte, una metáfora puede no tener el menor éxito de difusión y no por ello deja de ser un símbolo, mientras que una imagen del refranero no se constituye en símbolo hasta el momento en que es asumida y aceptada por toda la comunidad.

Todo ello nos lleva a considerar el valor connotativo del refrán. Habíamos clasificado los refranes en connotativos y denotativos, de acuerdo

19 Ver F. LÁzARo CARRETER, op. cit., p. 224. 
con su mayor o menor carga simbólica. La connotación se refiere a una parte muy importante del significado que trasciende las características inherentes y necesarias de aquello que se trata y concierne a todo lo que puede sugerir $-y$, por tanto, no inherente-, en la mente, tanto del emisor como del receptor del mensaje, en un contexto cultural dado.

El hablante, mediante el lenguaje, construye postulados que racionalizan la experiencia y, a la vez, le sirven y ayudan a ordenarla. Pero, a medida que el hombre avanza, la red de relaciones del mundo que le rodea también lo hace en su interior, con lo cual será capaz de establecer los más diversos parentescos, ampliándose así en gran medida la representación simbólica del individuo.

El mecanismo mediante el cual esa verbalización de las reglas que es el refranero, se sirve de aquella representación simbólica interior, es, básicamente, la alegoría. Hemos dicho el refranero y no el refrán; lo que con ello se pretende es distinguir claramente ambos conceptos, como conjunto uno y como elemento individual el otro, respectivamente. Cada refrán puede usar de diversas figuras retóricas - metáforas, metonimias, etc. - y no necesaria ni exclusivamente de la alegoría.

Sin embargo, el refranero ideológico como conjunto ha sido asumido por los hablantes como una alegoría. De ahí se deduce algo importante: el poder que posee el refranero de conseguir ser interpretado correctamente, puesto que tanto emisor como receptor podrán acceder a la información contenida en un refrán determinado, sea cual sea la forma en que éste se presente, gracias a ese valor alegórico generalizador del refranero. El notable número de refranes sinónimos en una misma lengua o, incluso, en distintas, son buena prueba de ello. Podemos citar al respecto refranes como: «Aún no ensillamos y ya cabalgamos», «Fijo no tenemos y nombre le ponemos», «El hijo por nacer y la papilla a herver», todos con el mismo significado; o bien «De tal palo, tal astilla» $y$ «El hijo de la gata ratones caza». Encontramos una misma idea reflejada en distintas lenguas, en los siguientes refranes: «Petit à petit, l'oiseau fait son nid», «Grano a grano, hincha la gallina el papo» y «Mica en mica s'omple la pica».

\section{OPERATIVIDAD DEL REFRÁN EN UN CAMPO SEMÁNTICO CONCRETO: EL MATRIMONIO}

Para ejemplificar el carácter instrumental del refrán, esa calidad de artefacto cultural que hemos venido exponiendo, lo haremos analizando algunos refranes referidos al matrimonio, por el indudable interés que, desde el punto de vista etnológico, presenta esta institución. Un notable número 
de estudios antropológicos se basan en la observación de las reglas que rigen las relaciones de parentesco de la pareja humana, institucionalizada en cada sociedad de acuerdo con su peculiar ideología.

Dentro de esta parcela del refranero pueden encontrarse consejos de tipo social como los siguientes: «Casar y compadrar, cada cual con su igual». «Casamientos de parientes, tienen mil inconvenientes». Se trata de consejos que proponen normas para establecer los límites en la elección del cónyuge - ni lejano, ni tan cercano que sea familiar-, con lo cual el terreno queda claramente acotado.

Otro tipo de consejos, más relacionados con la moral cristiana, son: «Compañía de dos, hízola Dios», "Más vale casarse, que abrasarse». En estos refranes se considera el matrimonio como obra divina y como salvación, ya que por medio de ese vínculo el hombre puede librarse del amor pecaminoso y, sobre todo, del fuego del infierno. El término clave es aquí «abrasarse», que juega un importante papel connotativo.

Otros refranes hacen referencia a la carga que supone un vínculo semejante: «El día que me casé, buena cadena me eché». "Casar, casar, suena bien y sabe mal». "Casarás y amansarás». «Madre, ¿qué cosa es casar? Hija, hilar, parir y llorar». Es decir, el matrimonio es un deber y como tal es una carga pesada de llevar, como una cadena. La situación es aún más dramática -incluso en la forma, ya que se trata de un diálogo- en el último de estos refranes, en el que el casamiento se contempla como una situación que cambia radicalmente la vida de la mujer, dado que sólo le ofrece trabajo duro, maternidad con dolor y penas sin cuento. Esto es lo que por medio de tres metonimias connota este poético refrán.

Asimismo, el refranero recomienda unas especiales características tanto para el marido como para la mujer: «El mejor marido, el que más ha corrido». "En el marido, prudencia; en la mujer, paciencia». "La buena mujer, ni ha de oir ni ha de ver». Sentencias todas que reflejan la clara superioridad social del marido frente a la mujer que debe mantenerse sumisa y sin exigencias. Porque cuando ocurre lo contrario, el marido es ridiculizado por su falta de energía: «Cuando la mujer manda en la casa, el marido es calabaza». "Mi marido es tonto y yo vivaracha; cuando yo salto, él se agacha». Pero si el marido es como «debe ser», es inaceptable que la mujer no se comporte como más arriba se ha aconsejado; por ello: «A mujer temeraria, o dejarla o matarla». "A la mujer y a la gallina, tuércele el cuello y te dará la vida». Refranes harto violentos que siguen reflejando esa clara superioridad masculina, ahora traducida en fuerza física.

También desde la perspectiva paterna se aprecia esa superioridad: el matrimonio por interés puede actuar como alivio para un padre que desea deshacerse de una hija conflictiva. «A la hija mala, dineros y casarla». 
En definitiva, vemos cómo la mujer no sale muy bien parada en lo que a consideración personal y social se refiere. Quizá el refrán que lo resume todo sea éste: «La mujer, si es hermosa, te la pegará; si fea te cansará; si rica, te gobernará y si pobre, te arruinará», en el que, se mire por donde se mire, no hay esperanza para ella.

Otra cuestión en la que el refranero se muestra inflexible está en el límite de tiempo aconsejable para contraer matrimonio: "Quien tarde casa, mal casa». "La que casa con un viejo, más lo ha por el pellejo». "Viejo casado con mujer hermosa es cosa muy dañosa».

Existen también numerosos refranes referidos a los lazos de parentesco establecidos por matrimonio, excluyendo a los cónyuges, que resultan muy ilustrativos: «La que no tiene suegra ni cuñada, ésa es bien casada». «El hijo de mi hija, pónmelo en la rodilla; el hijo de mi nuera, dale pan y vaya fuera». «A ti te lo digo, hijuela; entiéndelo tú mi nuera». "Amistad de yerno, sol en invierno».

Hasta aquí hemos revisado una serie de refranes que suelen interpretarse principalmente en sentido recto. Pero existe otro grupo de refranes que, si bien son igualmente referidos al campo semántico del matrimonio, tienen la facultad de poder ser interpretados en sentido figurado, aplicándose a situaciones y hechos que ya nada tienen que ver con el matrimonio en sí. Ello ocurre gracias al componente alegórico general del refranero, del que hablábamos anteriormente. Para el análisis de este tipo de refranes resulta interesante observar las glosas que los diversos recopiladores incluyen en sus colecciones. Tanto las colecciones antiguas como las modernas, suelen recurrir a estas glosas con el fin de dar un mayor sentido a su labor, lo cual apoya claramente el valor alegórico del refranero. Lo vemos en el siguiente refrán: «A la boda de D. García, lleva pan en la capilla». Glosa: "Que nadie tenga confianza en la hacienda de otro, por rico que sea» ${ }^{20}$.

En este refrán se observa cómo la «boda» es un mero pretexto, que se convierte en imagen para establecer una alegoría:

Boda de D. García $\longrightarrow$ Bienes ajenos

Llevar pan en la capilla (propia) $\longrightarrow$ Contar tan sólo con lo de uno olvidando lo ajeno.

Es probable que, de ser posible rastrear el origen de este refrán, nos encontráramos con una situación - fiel a la letra-, un cuento quizá, dada en la boda de algún personaje que no supo obsequiar adecuadamente a sus invitados. Ello permanecería en la memoria popular, dando pie al refrán en cuestión. Este, al utilizar el presente («lleva») en un verbo que se relaciona con un personaje y una situación concretos, pertenecientes a un

20 Glosado por Hernán Núñez. En F. C. Maldonado, op. cit., p. 50. 
tiempo pasado, incide en el aspecto intemporal propio del refranero -es claro que D. García no va a estarse casando siempre- y le otorga ese carácter general alegórico basado en la aplicación e interpretación, por parte de emisor y receptor, del sentido figurado que aquí prevalece claramente.

Lo mismo ocurre en los siguientes refranes: «No hay boda sin tornaboda». Referido a que siempre debe agradecerse cualquier dádiva o invitación devolviendo el don en igual medida. De nuevo, el término «boda» es una imagen que remite a otro concepto distinto del acontecimiento social que habitualmente significa. «Bien o mal, casaros han; ora sea con Pedro ora sea con Juan». «Casadica de vos dicen mal; digan digan, que ellos cansarán». En ambos refranes se alude a las murmuraciones y maledicencias y a la actitud de indiferencia a tomar ante ellas.

Los siguientes refranes vuelven a utilizar la palabra «boda» en tanto que imagen de otra idea: " $A$ boda ni bautizado, no vayas sin ser llamado», refrán dirigido a los entrometidos, y «La que no baila, de la boda se salga», dedicado a aquellos que no saben comportarse adecuadamente en cada situación.

Aún otros más: «Si de ésta escapo y no muero, nunca más bodas al cielo». «Tras que la novia es tuerta, peyóse la malhadada» ${ }^{21}$. Glosa: «Al infortunio nunca le faltan desgracias» ${ }^{22}$.

Tanto en uno como en otro es patente la aplicación alegórica, ya que no tendrían estos refranes demasiada razón de ser por su sentido recto ${ }^{23}$.

\section{CONCLUSIONES}

Hemos visto cómo el refranero resulta elemento valioso para el análisis de las relaciones entre lengua y cultura, debido, principalmente, a su carácter instrumental al servicio de una ideología que se manifiesta por medio de la alegoría que lleva implícita. Esta idea existía ya en ciertos autores del siglo XVI. Juan de Mal Lara nos da a entender, en su Pbilosophia Vulgar, que el estudio de los refranes debe consistir en la indagación de lo «filosófico» que, en voz del pueblo, se transmite de unas generaciones a otras. Pero, para este autor era importante - y ahí radica la modernidad de su

21 «Peyóse»: «Se empeoró».

22 Glosado por Marqués de Santillana. En SBARBI op. cit., p. 147.

23 Dado un contexto cultural preeminentemente católico, la boda no es algo de lo que se pueda escapar: uno, o se casa o no se casa. Sin embargo, si se desea huir de tal situación, ello constituye un acto de voluntad cuyo matiz no se aprecia en el primero de estos refranes, en el que el sujeto parece esperar que algo indeterminado acuda en su auxilio. En cuanto al segundo, éste describe una situación tan caricaturesca que difícilmente puede ser aplicada a un hecho real. 
observación- averiguar las razones de las diversas interpretaciones de los refranes. Dice:

Púseme a preguntar a muchos que dezían refranes porqué dixo más aquel que otro; cómo juntava aquella conclusión con las razones primeras, como si dixesse de un hombre que anda perdido buscando y acude a cualquier parte, assi que quien "bueyes ha menos, cencerros se le antojan". Sabíanlo quadrar, pero dezir porqué se dixo, de adónde vino, qué movió a los antiguos dezir más "bueyes" que otros animales, entonces callavan todos, y con dezir "No sé más de que assí lo usan mis padres y los que conozco" 24 .

Lo que de todo esto se desprende es que el refranero, partiendo de unas situaciones concretas, provee de unas reglas de conducta, convivencia, etc. que no vienen verbalizadas de forma directa sino a través de formulaciones que se apoyan en coordenadas y puntos de referencia pertenecientes a una cultura determinada, que aquí se ha estudiado observando el ámbito del matrimonio.

Todo ello contribuye a la configuración de una ideología muy poderosa que, aunque hoy ha perdido parte de su vigencia sigue actuando sobre los miembros de nuestra sociedad.

En cierto sentido, lo que aquí se ha tratado de reflejar tiene algo que ver con el proceso de «catálisis cultural» del que nos habla el profesor Marsá ${ }^{25}$. Esta acción catalítica es atribuida a un componente cultural, no siempre evidente, pero que puede rastrearse.

Algo parecido ocurre en el refranero, con la diferencia de que, en este caso, resulta verdaderamente difícil hallar ese componente específico que facilita la catálisis, como Mal Lara indicaba (¿por qué bueyes y no otros animales?).

Probablemente ese componente esté bajo capas y capas de tradiciones e historias imposibles de desentrañar ya en nuestros días. Pero puesto que se trata de un fenómeno cultural que afecta a buena parte del refranero, puede afirmarse, sin grave riesgo de error, que esa acción catalítica viene aquí dada, no de una forma puntual por un componente específico, sino por toda una red ideológica que se ha ido tejiendo a lo largo del tiempo y que se nos presenta por medio de la alegoría. Ya Mal Lara observó que las gentes, el significado de los refranes «sabíanlo quadrar» mas no sabían decir por qué.

${ }^{24}$ J. de Mal LARa, Philosophia Vulgar. Citado por F. SÁnChez y EsCribano, «Algunos aspectos de la Philosophia Vulgarm. RFE, XXII (1935), pp. 282-283.

25 F. MARSÁ, «Catálisis cultural en procesos semánticos», Éthnica, n." 3 (1972), pp. $85-98$. 
En definitiva, el refrán ha sido un elemento muy valioso para el hablante: por una parte le ofrecía unas pautas formales que le ayudaban en su competencia lingüística; por otra, se le presentaba como un amplio abanico de posibilidades de utilización: según el uso, el refrán cobraba su significado pleno para cada ocasión. Si utilizamos el pasado es porque hoy, sin duda, los refranes no juegan el papel que antaño desempeñaron. Sin embargo, constituyen una herencia cultural que no puede desdeñarse, pues nos ayuda a desvelar ciertas pautas ideológicas de nuestra cultura.

\section{Nieves Vila Rubio \\ Facultad de Letras. \\ Estudio General de Lérida.}

Partiendo de la precisión de los conceptos de cultura y de cultura popular, la autora examina aquí el carácter instrumental del refrán y cómo éste ha sido utilizado según ideologías, de la misma forma que cualquier otro artefacto cultural. De ello resulta la consideración del refranero en bloque como una alegoría. Refuerza esta teoría el análisis que realiza de un conjunto de refranes pertenecientes al campo semántico del matrimonio.

Taking into account the precision of the concepts of culture and popular culture, the author examines the instrumental character of the «refrán» and how it has been used according to some ideologies; this has made possible that the whole "refranero" may be considered as an allegory. In order to support this theory the author analyses some of these Spanish proverbs belonging to the semantic field of marriage. 